\title{
Science: a means of locating resources
}

Cometimes I fear that we may lose sight of a few realities when we relate science and technology to development. We must be a little guarded, in case too much of the burden for economic development and advancement of countries be placed on the shoulders of science and technology, as a result of which it will be blamed for the failures which will inevitably occur. Science and technology cannot provide. in themselves, the motivation necessary for development. This lies with the political will and in the social drive of the individuals and communities of a country, both in recognising their opportunities and realising them.

In demonstrating that science and technology are nevertheless critical for development, I will limit my comments to economic development. This is not to ignore the social and cultural aspects, or minimize their significance, but because they require a rather different approach. Nor am 1 concerned, herein. with the current questioning of the value of economic development. as this can too easily generate only social palliatives instead of pragmatic solutions to poverty and inequity. and result in calls for the simple redistribution of wealth at the cost of increasing it overall. It is a separate issue.

The purpose of economic development, is, by and large, the increase in the production of wealth; and the production of wealth takes place by the application to natural resources of man's labour. Under natural resources, I include not only all natural phenomena and associated resources, renewable and non-renewable, transformable and non-transformable, but also the land itself. These are not the product of man. Labour, in this context, is the effort by man which arises from the application of his hands. brain and the tools which his brain has shown him will increase his efficiency. Thus, wealth is the product of man and his resources, which, obvious as it may seem, is often forgotten, as one too frequently reads of natural resources or human resources being regarded as wealth by themselves. The same applies to the scientific and technological capacity of a society. The point is important because loose thinking on it confuses the issues of the production and distribution of wealth and leads to a loss of objectivity in economic development and the assistance which

This is a shortened version of a paper presented to a recent meeting on UNCSTD convened by the World Federation of Scientific Workers. The full paper will appear, along with others, in the Report and Documentation of the conference currently being prepared by the Federation.

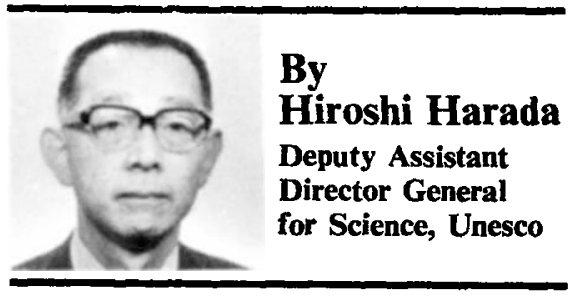

science and technology can offer it.

The relationship of science and technology to the production of wealth can be seen once it is recognised that a natural resource is no use until it has been found, described and understood. Science, to an increasing degree, is the identifying process in bringing resources into the production of wealth. Technology, however, is related to labour, and the level of technology possessed by labour is the index of its efficiency. Given unlimited natural resources, wealth may be increased without improvement in technology, but with limited natural resources technology must be improved.

This provides a degree of distinction between many developed and developing countries. In general, the former have increasingly to develop their technological capacity, whilst the latter have. for the most part, still to ensure that their natural resources have been identified scientifically and fully realised economically.

It is important to determine, therefore, if the balance demanded between science and technology is, for any country, the right one in relation to its stage of development and knowledge of its resources. There is a real danger that the cart is being put before the horse: that the developing countries are trying to launch into advanced technologies without an adequate economic justification, when they should still be seeking to upgrade their scientific capacity for its tasks both

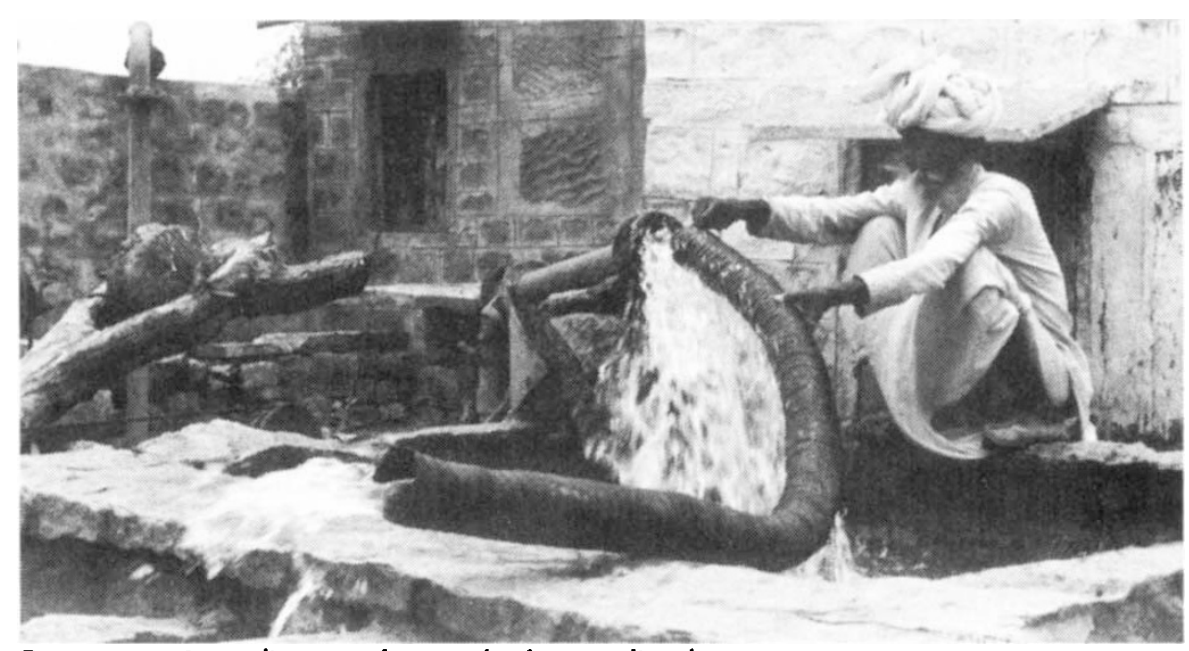

Resources: science discovers them, technology applies them of inventory taking and application to renewable resources. Technology is a requirement of circumstances, not an economic panacea. The 'technological gap', as it is called, is as much a reflection of the different needs of countries as it is of restrictive practices, justifiable or otherwise.

The situation must also be seen within the time and circumstances within which it occurs. It has been noticeable that, particularly in countries which in the last decade or so have divested themselves of colonial rule, there has been a decline in the output of the scientific establishments responsible for natural resource inventories and improvement of the yields from renewable resources. This has arisen because of the need of these countries to establish or strengthen their capacity to train their own scientists.

This is a major task, the priority for which has inevitably drawn scientific and technical manpower into the universities, often with better conditions and facilities than exist in the much older applied science establishments. Only now does one see the newly-trained manpower beginning to refill them. It will need more time before able scientists will seek opportunities in industry and only then if its productive capacity and size will sustain viable research and development departments. It is at this stage that the transfer of advanced technologies will really become significant, not only because of the need, but also because there will be an adequate indigenous scientific capacity not only to seize and adapt it, but also, and perhaps more important, to create it.

1 think, also, that it is a well to remind ourselves of the basic differences between, and the origins of, science and technology. There seems to be a tendency for administrators, in particular, to regard them as being 
largely similar in quality and thus to be mutually interchangeable and competitive on the same terms. The development of the so-called applied sciences has further tended, in providing a link between the two, to blur the issue. The result has been, I feel, an over-emphasis on the need for science to justify itself in the same way as does technology, and to have an immediate, direct and finite impact on socio-economic problems. Many scientists have subscribed to this, even if unconsciously, in the search for support for their activities. This too often leads to a shortfall in promises regarding its utility in the eyes of administrators and further strengthens their doubts about the efficacy of science compared to technology.

Science, or demonstrable knowledge, is open-ended and has a separate existence. It can be pursued for its own sake, having a cultural value as deeply felt and satisfying as that resulting from the study of art or the humanities, while still serving to relieve man's condition. Technology, in its usually accepted sense, has no existence separate from the material production in which it is involved or for which it was created. Science starts with man's basic curiosity about his environment; whereas technology starts with man's basic economic urge to carry out more easily or profitably a productive activity.

Science. almost by definition, is nonexistent until it has been communicated (transferred) to others. Technology has its proof in its products and, therefore, needs not itself to be transferred, thereby conferring rights to its personal ownership and a truly commerical value. Its 'excellence', if I may apply the term, is self-evident. Science, however, needs to be patronised, because its value and excellence is not readily apparent, particularly to administrators. They have to monitor its achievements and excellence, particularly in its more basic aspects, through scientists; and this has, and always will be, an act of faith on their part, which is not a basis for resource allocation they like, particularly since the demand has reached the level it has, today.

Science and technology have been joined in modern times only because much advanced technology has to be science-based; it is now more often manufactured in research and development departments than invented by simple intelligence and manual skill. This, however, does not alter the nature of science and technology, although it does increase the role of science in the production of technology and further emphasises the need for its development.

This brings me to my main point for developing countries, which is that in seeking economic and technical inde- pendence, particularly in decisionmaking, they must strengthen their scientific and engineering cadres, not only in their numbers and disciplines, but also in their excellence and problem-solving ability, which latter is the first step to the provision of a genuine indigenous technological capacity. This requires the dynamic teaching of science from the secondary levels of education, through inspired guidance of senior students at the university level, to strictly disciplined research work at the post-graduate level. It means fostering scientific societies, both learned and professional, and the establishment of a stable corps of scientists large enough to be viable and self-critical. It involves increasing considerably the number and quality of

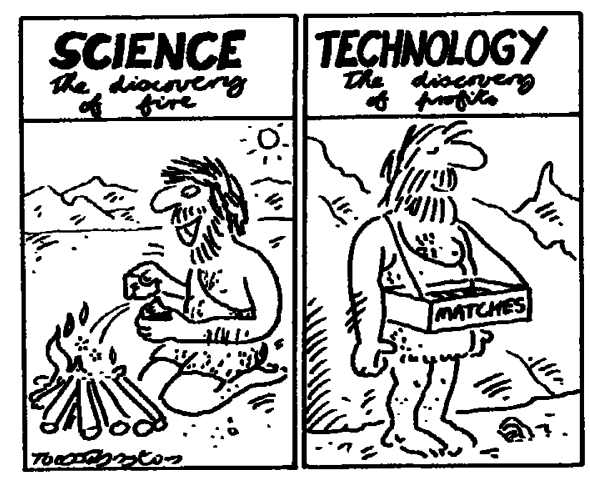

the technical cadres, because most developing countries are characterised by poor ratios of technicians to scientists, which means that any technological improvement or change the latter may prescribe cannot be widely applied.

All this takes a long time and there is no short cut, least of all that based on too early attempts to introduce technologies for which the indigenous technical capacity to handle it is inadequate or absent. We have already seen the mistakes resulting from trying to introduce the applied sciences before the basic sciences are adequately established. To repeat the error in respect of advanced technologies is a greater mistake and can mean an even more extended thraldom, through expensive patents and licenses, to technologies created originally for developed countries.

Moreover, if it is the contention of many developing countries, as it seems to be, that many of these technologies are inappropriate, for whatever reason, technical, ecenomical or social, then it is an even more self-defeating choice as a way to indigenous development. And, it carries with it the threat of limiting the resources for indigenous scientific effort and, thereby, the exploration for, and discovery of, the natural resource potential of a country. which again brings me back to the point I made earlier, namely, that I believe many of the developing countries need to complete their natural resources inventories before launching into an era of high technology.

I feel that for the realisation of UNCSTD's primary purpose, which is the strengthening of the indigenous technological capacity of countries, that we must think not only of the problems of the choice and transfer of technology but also of the establishment of the right balance between science and technology for development of any country.

Although Unesco's own responsibilities are primarily concerned with the promotion of, and international cooperation in, the natural sciences, whereas other UN agencies have the prime responsibilities for these in the applied sciences, Unesco has increasingly emphasised the important role of natural sciences in relation to the identification and development of the natural resources of developing countries. It is still concerned about the inadequacies both in policy-making in this field and in the creation of effective manpower resources to implement the policy.

In respect of the transfer of technology, Unesco recognises that the problem is much more complicated than that posed solely by the difficulties of gaining access to a particular technology. It involves the creation of a technologically-minded community, not only at the higher levels of specialisation but also at the lower levels of comprehension, where standards and excellence of technical handling are essential for the development of a genuine indigenous capacity which can respond to the needs and opportunities presented to it. Without the development of this basic ability, the transfer of technology alone will remain unfruitful in the long run and tend to separate the communities involved.

For both these reasons, Unesco still stresses the importance of the role of education as one, at least, of the technical prerequisites for strengthening the scientific base of a country and for the successful importation and application of technology. It is, of course, not the only prerequisite. There are social and environmental constraints involved also in the transfer of technology and Unesco has developed programmes in these two fields to examine them and discuss the socio-cultural conditions likely to foster indigenous development processes.

Unesco's activities in this matter of science and technology for development, however, are limited by the availability of funds and the degree of international cooperation it can obtain. We hope that UNCSTD will urge the Member States to be more generous and far-seeing in both these. 